who also wander up to the snow line. At a height of 13,000 feet he saw three elephants, and at night the shrill trumpeting of these animals could be heard round the station. On October 18 he found himself, most unwillingly, obliged to leave the elevated settlement and return to Taveita. The relatively great cold they had experienced had reacted very unfavourably on his men' health, and he feared that a longer delay might render them quite unfitted to carry burdens. He intended, however, to make his return journey entirely through a new and hitherto untraversed country, and this project somewhat consoled him for leaving the summit of Kilimanjaro still unconquered. Their downward journey, part of the way through trackless bush and dense dank forest, was not without adventure and some reward in scenery of great beanty. The average elevation of this country was between 8000 and 7000 feet, and the temperature consequently almost cool, ranging from $43^{\circ}$ at night to $70^{\circ}$ in the mid-day warmth. After some four hours' walking from their camp they crossed the long ridge that marked the southern tlank of Kimawenzi, and began to descend the eastern slope of the mountain. Soon they emerged on a kind of heath-like country, and then looked forth on a splendid view stretching from Mwika to the mountains of Bura and Ukambani (the Kiulu range), with Jipe on one hand and the River Tzavo on the other. After some enjoyable excursions from his settlement at Taveita, finding that his funds would not support the expedition beyond the end of November, he made a rapid journey to the coast by way of Pare, Usambara, and the Rufu river to Pangani. At Zanzibar, finding there were no fresh funds to enable him to return to Kilimanjar s, he paid off the last of his faithful followers, many of whom had accompanied Thomson on his great journey, and took his passage on the British India steamer to Suez in quite a sulky frame of mind, as sorry to leave his beautiful mountain as many people are to quit England. Travelling overland from Suez, he arrived in London not much more than six weeks after he had caught his last glimpse of the snows of Kilimanjaro.

\section{A SCANDINAVIAN LAND OF OPHIR}

IVE learn from Noturen that the little island in the Hardanger Fjord, known as Bömmelöen, which two years ago was an uninhabited and desolate spot, is now a busy scene of extensive gold-digging. Numerous English artizans and Norsk bricklayers and carpenters have for months been actively engaged in boring and sinking shafts into the ro:k, and in preparing houses and shelter for the men and machinery that have been drawn hither by the report of the discovery in $\mathbf{1} 882$ of gold in the Storhangen mine. This discovery had been anticipated in $\mathbf{1} 862$ by the find of a piece of pure gold, which was at once deposited in the mineralogical museum of Christiania, where it has since remained apparently unheeded, although the place and time at which it was found are duly marked on the corresponding label. After twenty years gold was again found in 1882 , at the Storhangen mine, which was then being worked for copper ore. The result of this discovery was the purchase, in 1883 , of the works by an English firm, trading under the title of the Oscar Gold Mining Company, which is worked under the scientific direction of Mr. Murchison. Considerable amusement seems so have been created among Norsemen by a somewhat ambiguous statenent, set forth in the Company's circulars, which oracularly announces that "the gold finds at Bömmeloen are either Nature's greatest success or her greatest illusion"!

The geological formation of Bömmelöen is similar to that of other auriferous rocks, the gold being found in quartz, which occurs in strata never wore than six feet thick, although of considerable extent, and generally underlying green (chloritic) schist. The greenstones of the island differ from those found in other parts of Norway, and contain glass and various typical vulcanic products.

The operations of the Oscar Mining Company have given a new stimulus to the search for gold in Norway, and we learn that Herr Bakke, Inspector of Mine : at Trondhjem, has officially reported the discovery of virgin gold in a piece of chloritic slate from Stegen in Nordland, while it is authoritatively stated that gold has been found within the last year or two at Sveen in the Bergen-Amt, and also near Stavanger. In the latter case the discovercr, Nils Berg, an old experienced Australian golddigger, washed the gold from the mud remaining at the bottom of a shaft that had been sunk in a copper mine.

\section{SCIENTIFIC SERIALS}

Wiedenann's Annalen, vol, xxiv. January 1885-0. Lehmann, on the melting-points of bodies in contact, and on the electrolysis of solid iodide of silver. A remarkable paper, accompanied with an elaborate plate describing phenomena of crystallisation observed chiefly with microscope at limiting edge of two crystallisable liquids or solutions. Iodide of silver presents certain closely-related phenomena under electrolysis, both in molten and in solid condition. Regular crystalline iodide of silver conducts an electric current, the silver being carried in the direction of the negative current through the crystal without its structure being clisturbed. In its electrolysis, however, there appears a streaking in the direction of the flow of the current. W. von Bezold, on a new kind of cohesion-figures. These experimental researches relate to the quasi-dendritic forms observed when one liquid descends through another.- $\mathrm{L}$. Boltzmann, on the possibility of founding a kinetic theory of gases on attractive forces alone. This is an attempt to dispense with Maxwell's hypothesis that molecules repel one another in the inverse fifth power of the distance, which he framed to account for the apparent perfect elasticity exhibited by molecules of gases. Boltzmann proposes a new theory, based on attraction, very similar to that recently independently propounded by Sir W. Thomson (NATURE, August 28, 1884).-O. Chwolson, on the calibration of the plug-rheostats of Siemens and Halske. This discusses corrections for the resistance of connecting-pieces, \&c.-F. Kohlrausch, the electric conductivity of water distilled in vacio. A column of pure water I metre long and of I square millimetre section has a resistance of about $4 \times \mathrm{IO}^{10} \mathrm{ohms} .-\mathrm{G}$. Kirchhoff, on the change of form which an clastic body expcriences when it is magnetically or dielectrically polarised. This paper, originally published in the Procedings of the Berlin Academy, deals analytically with the phenomenon of electrostriction investigated by Lorberg and others.-A. Schuster, on the discharge of electricity through gases. Treats of certain points in dispute between the author and Profs. Goldstein and E. Wiedemann. The author pronounces in favour of the view that all the phenomena of effect of magnetism, \&c., upon the discharge of the negative electrode may be explained if it be admitted that the negatively-charged portions of the gaseous molecules are driven off from the kathode.--E. Goldstein, on electric conduction in the vacutum. Discusses some experiments in which a carbon filament lamp was employed; the filament forming one electrode, a platinum wire being inserted through the glass to serve as another electrode for the discharge, which was obtained, without an induction-coil, with electromotive forces of about 300-350 volts. - Werner Siemens, contribulions to the theory of magnetism. Describes experiments on partially-closed magnetic circuits of iron, giving rise to the opinion, that the harder a specimen of iron is, the greater is the value of the magnetising force at which the maximum of permeability is observed. Also, the magnetic resistance of air is from 480 to 500 times as great as that of iroll.-II. Hertz, on the dimensions of unit of magnetic pole strength in different systems of measurement.-E. Ketteler, the optical constants of magnetic media. Develops equations relaring to Kundt's recent magnetooptic observations. - E. von Fleischl, the doulle refraction of light in fluids. Proves that in optically-active liquids the rotation is due to the existence of double refraction. Doublerefracting liquids have no optic axis, and the wave-surface consists of two concentric ppherical sheets.-W. von Voigt, on the measurement of the refractive indices of absorbing media. Recommends the prism method as more accurate than the totalreflection method. - W. von Voigt, on the theory of reflection and refraction at the boundary of crystalline media. New equations based on the aithor's theory of the reactions between matter and ether in transparent media, and leading to same conclusions as Kirchhoff's older theory.

Fournal de Physique, November, I884. - I. Jamin, on hygrometry. The author proposes to substitute for the "relative humidity "a new coefficient termed the "hygrometric richness," which is the ratio of the actual pressure of aqueous vapour of the air to the difference between the total atmosplieric pressure and the actual vapour pressure. The substitution appears to be both rational and instructive.- Ch. Rivière, essay on cooling power of gases. Confirms formula of Dulong and Petit up to $400^{\circ} \mathrm{C}$., but above that temperature the observed value : are lower than the theoretical. Also appears to prove that at very low pressures cooling power is independent of the chemicul craposition 